Institute for Food Hygiene and Safety

of the Vetsuisse Faculty, University of Zürich

Director: Prof. Dr. Roger Stephan

Scientific supervision was provided by

PD Dr. Claudio Zweifel

\title{
Application of a real-time PCR-based system for monitoring of O26, 0103, O111, O145, and 0157 Shiga toxin-producing Escherichia coli in cattle at slaughter
}

\section{Inaugural-Dissertation}

to be awarded the Doctoral Degree of the

Vetsuisse Faculty, University of Zürich

submitted by

Eveline Hofer

Veterinarian

from Uster, Switzerland

approved on proposal from

Prof. Dr. Roger Stephan, Referent

Zürich 2012 


\section{Application of a real-time PCR-based system for monitoring of $\mathbf{0 2 6}, \mathbf{O 1 0 3}$,}

\section{O111, O145, and 0157 Shiga toxin-producing Escherichia coli in cattle at}

\section{slaughter}

Running head: O26, O103, O111, O145, and O157 STEC in cattle

Eveline Hofer ${ }^{1}$, Roger Stephan ${ }^{1}$, Martin Reist $^{2}$, and Claudio Zweifel ${ }^{1 *}$

${ }^{1}$ Institute for Food Safety and Hygiene, Vetsuisse Faculty University of Zurich, Zurich, Switzerland

${ }^{2}$ Veterinary Public Health Institute, Vetsuisse Faculty University of Bern, Bern, Switzerland

*Corresponding author: Claudio Zweifel, Institute for Food Safety and Hygiene, Vetsuisse Faculty University of Zurich, Winterthurerstrasse 272, CH-8057 Zurich, Switzerland. Phone: +41 44635 8651, Fax: +41 44635 8908, E-mail: ils@fsafety.uzh.ch

Accepted for publication in Zoonoses and Public Health

In fulfillment of the doctoral thesis of Eveline Hofer 


\section{Contents}

Summary 3

Impacts $\quad 4$

Introduction $\quad 5$

Materials and methods $\quad 6$

$\begin{array}{ll}\text { Results } & 9\end{array}$

$\begin{array}{ll}\text { Discussion } & 10\end{array}$

References 14

$\begin{array}{ll}\text { Tables } & 19\end{array}$

Acknowledgements 22

$\begin{array}{ll}\text { Curriculum vitae } & 23\end{array}$ 


\section{Summary}

Fecal samples were collected from 573 slaughtered cattle aged between three and 24 months in seven abattoirs. After enrichment (mTSB with novobiocin), samples were screened by real-time PCR first for stx and if positive, tested for the top-five STEC serogroups using PCR assays targeting genes specific for serogroups O26, O103, O111, O145, and O157. Of 563 samples with available results, $74.1 \%$ tested positive for stx genes. Amongst them, the serogroups O145, O103, O26, O157, and $\mathrm{O} 111$ were detected in $41.9 \%, 25.9 \%, 23.9 \%, 7.8 \%$, and $0.8 \%$, respectively. From 95 O26, 166 O145, and 30 O157 PCR-positive samples, 17 O26, 28 O145, and 120157 strains were isolated by colony hybridization after immunomagnetic separation. The 17 O26 strains were eae-positive but only nine strains harbored stx (eight possessing stx 1 and one stx2). Of the 280145 strains, ten were eae-positive including four harboring stx 1 or stx2, whereas 18 were negative for stx and eae. Five of the 120157 strains harbored stx2 and eae, did not ferment sorbitol, and were identified as STEC O157:H7/H'. The other seven $\mathrm{O} 157$ strains were negative for stx and eae or positive only for eae. Shiga toxin genes and the top-five STEC serogroups were frequently found in young Swiss cattle at slaughter, but success rates for strain isolation were low and only few strains showed a virulence pattern of human pathogenic STEC.

Keywords: Shiga toxin-producing Escherichia coli; top-five STEC serogroups; cattle; real-time PCR; strain isolation. 


\section{Impacts}

- Using a real-time PCR-based system, Shiga toxin genes were frequently found in young Swiss cattle at slaughter $(>70 \%)$ and the top-five STEC serogroups, especially O26, O103, and $\mathrm{O} 145$, were also detected.

- Success rates for strain isolation from bovine fecal samples were low and only a few of the isolated strains showed a virulence pattern of human pathogenic STEC.

- The value of a STEC screening aiming at the top-five serogroups with the described approach in slaughtered cattle remains questionable, especially as long as fast and reliable isolation of strains is not warranted. 


\section{Introduction}

Shiga toxin-producing Escherichia coli (STEC) are responsible for human gastrointestinal illnesses, including non-bloody or bloody diarrhea (Kaper et al., 2004; Karch et al., 2005). These conditions may be complicated by neurological and renal sequelae, including the life-threatening hemolytic-uremic syndrome (HUS), which is the main cause of acute renal failure in children (Tarr et al., 2005). Most outbreaks and sporadic cases of bloody diarrhea and HUS have thereby been attributed to STEC O157:H7. STEC have been isolated from the intestines of a variety of healthy domestic and wild animals, but ruminants, mainly cattle, are regarded as the principal reservoir of STEC (Caprioli et al., 2005; Karmali et al., 2010). The majority of human infections are correlated with the consumption of fecally contaminated food and water, but transmission by animal-to-person and person-to-person contact has also been reported. STEC are characterized by the production of one or more Shiga toxins: Stx1, Stx2, and variants (Johannes and Römer, 2010). Pathogenic STEC tend to feature Stx2 and intimin mediating attaching and effacing lesions on intestinal epithelial cells (Friedrich et al., 2002; Brooks et al., 2005; Orth et al., 2007).

In the European Union (EU), Directive (EC) 99/2003 on the monitoring of zoonoses and zoonotic agents requires monitoring for STEC along the food chain. In 2009, the European Food Safety Authority (EFSA) published technical specifications for STEC surveys to ensure EU-wide standards (EFSA, 2009). According to a risk-based sampling strategy, these specifications aim at estimating the prevalence in young cattle (and sheep) at slaughter. Monitoring for STEC belonging to serogroups $\mathrm{O} 26, \mathrm{O} 103$, O111, O145, and O157, the so-called top-five serogroups (Beutin, 2006; Johnson et al., 2006), is thereby proposed (EFSA, 2009). The ISO 16654:2001 method is recommended for detection of Escherichia (E.) coli $\mathrm{O} 157: \mathrm{H} 7$, and the use of draft CEN TC275/WG6 standard (submitted to ISO for evaluation) is proposed for detection of serogroups O26, O103, O111, and O145. This standard is based on real-time PCR-based screening followed by a strain isolation step. Primers listed for use in PCR assays (stx, O26, 
O103, O111, O145, O157) were developed by Perelle and colleagues (Perelle et al., 2003; Perelle et al., 2004; Perelle et al., 2005). Based on the same primers, the closed GeneDisc ${ }^{\circledR}$ multiplex real-time PCR system (Pall GeneDisc Technologies, Bruz, France), which was recently evaluated by Beutin et al. (2009), is commercially available.

The aims of the present study were (i) to screen bovine samples by real-time PCR for Shiga toxin genes and if positive for the top-five STEC serogroups O26, O103, O111, O145, and O157, and (ii) to isolate strains from O26, O145, and O157 PCR-positive samples. Thus, application and challenges of a real-time PCR-based system for monitoring of O26, O103, O111, O145, and O157 STEC in slaughtered cattle were evaluated.

\section{Materials and methods}

\section{Abattoirs and sampling}

This study was based on investigation carried out within an 11-month period (January to November 2011) in seven abattoirs (A-G). Abattoirs were selected to get a widespread sample distribution throughout Switzerland and the five biggest abattoirs slaughtering cattle were included (A-E). Two smaller abattoirs located in southern Switzerland (F, G) were also included in the study because only few cattle from southern Switzerland were slaughtered in the abattoirs A-E. The present survey was part of a project of the Federal Veterinary Office evaluating the abattoir level as data source for monitoring programs.

Cattle aged between three and 24 months were sampled. Such animals tend to shed STEC more frequently and EFSA recommends investigating cattle within this age spectrum (EFSA, 2009). The minimum number of samples was calculated with the assumption of an infinite population size, a prevalence of $50 \%$, a desired confidence level of $95 \%$ and an accuracy of $5 \%$. In total, 573 bovine fecal samples were examined. From animals delivered together to the 
abattoir, not more than one animal was sampled. Fecal samples were preferred to hide samples to avoid potential cross contaminations and for practical reasons as a precedent pilot survey showed that they were easier to obtain. Fecal samples were collected from the large intestine using swabs after evisceration. After opening the large intestine and sample collection, swabs were placed in sterile bags and transported to the laboratory chilled.

\section{Screening for Shiga toxin genes and serogroups $026,0103,0111,0145$, and 0157 by real-} time PCR

Upon arrival at the laboratory, samples were enriched in modified tryptic soy broth (mTSB, CMO983, Oxoid AG, Pratteln, Switzerland) with $16 \mathrm{mg} / 1$ novobiocin (novobiocin sodium, Sigma-Aldrich Chemie GmbH, Buchs, Switzerland). Therefore, $20 \mathrm{ml} \mathrm{mTSB}$ were added to each of the bags with the swabs, the bags were stomachered and incubated for $12-18 \mathrm{~h}$ at $37^{\circ} \mathrm{C}$. From $50 \mu 1$ of the enrichment broth a lysate was made (lysis tube, Pall GeneDisc Technologies, Bruz, France). All samples were screened by real-time PCR in a first step for stx and in a second step (only the stx positive samples) for the serogroups $\mathrm{O} 26(w z x), \mathrm{O} 103(w z x), \mathrm{O} 111(w b d \mathrm{I}), \mathrm{O} 145$ (ihp1), and $\mathrm{O} 157$ ( $r f b \mathrm{E})$ with an open LightCycler-based system (LightCycler 2.0, Roche Diagnostics AG, Rotkreuz, Switzerland) or the commercially available, closed GeneDisc ${ }^{\circledR}$ system (Pall GeneDisc Technologies). Primers and probes (Table 1) were the same for both approaches and are in accordance to the requirements of CEN TC275/WG6 standard. The commercially available GeneDisc $\mathbb{R}$ system allowed simultaneous detection on multiple targets in 36 reaction microchambers preloaded with the necessary reagents (Beutin et al., 2009), and was performed according the manufacturer's instructions. For the LightCycler system primers and probes were purchased from Microsynth (Microsynth AG, Balgach, Switzerland). Amplification was performed with $20 \mu \mathrm{l}$ of reaction mixture containing $1 \mathrm{x}$ concentration of QuantiFast ${ }^{\mathrm{TM}}$ Multiplex PCR+R Kit (Qiagen AG, Hombrechtikon, Switzerland), $1 \mu \mathrm{M}$ of each primer, $200 \mathrm{nM}$ 
of each probe, and $2 \mu \mathrm{l}$ of template DNA. Amplification conditions for the LightCycler assays were $5 \mathrm{~min}$ at $95{ }^{\circ} \mathrm{C}$ followed by 45 consecutive cycles of first $30 \mathrm{~s}$ at $95{ }^{\circ} \mathrm{C}$ and then $30 \mathrm{~s}$ at 60 ${ }^{\circ} \mathrm{C}$, and a cooling step of $1 \mathrm{~min}$ at $40{ }^{\circ} \mathrm{C}$.

\section{Strain isolation}

From samples positive for stx and serogroups O26, O145, or O157, strain isolation was attempted. Therefore, $1 \mathrm{ml}$ of the first enrichment broth was incubated in $10 \mathrm{ml}$ of brain heart infusion (BHI) broth (CM1135, Oxoid AG) overnight at $37^{\circ} \mathrm{C}$. One milliliter was used for the respective $(\mathrm{O} 26, \mathrm{O} 145, \mathrm{O} 157)$ immunomagnetic separation according to the manufacturer's instructions (Dynabeads ${ }^{\circledR}$ EPEC/VTEC, Invitrogen Corporation, Zug, Switzerland). Diluted aliquots were plated onto sheep blood agar $\left(\right.$ Difco $^{\mathrm{TM}}$ Columbia Blood Agar Base EH, Becton Dickinson AG, Allschwil, Switzerland; 5\% sheep blood SB055, Oxoid AG) and incubated overnight at $42{ }^{\circ} \mathrm{C}$. Probes for colony hybridization were prepared by labeling serogroup-specific amplicons (PCR products generated with the same primers that were used for the serogroupspecific PCR assays) with PCR DIG Probe Synthesis Kit (Roche Diagnostics AG). Colony hybridization was performed according to the manufacturer's protocol for hybridization with DIG-labeled probes (Roche Diagnostics AG). Briefly, colonies were transferred to a nylon membrane and lysed following standard methods. After washing, cross-linking, and prehybridization in DIG-Easy-Hyb buffer for about $60 \mathrm{~min}$ at $42{ }^{\circ} \mathrm{C}$, hybridization with serogroupspecific probes was performed overnight at $42{ }^{\circ} \mathrm{C}$. After washing and blocking, the presence of labeled probe was detected with an alkaline phosphatase-conjugated antibody detection kit and NBT/BCIP stock solution. One to four positive colonies were picked from the sheep blood agar and the respective serogroup was confirmed as described above (LightCycler 2.0). Isolated strains were then examined for the presence of $s t x 1$, stx 2 , eae encoding intimin, and $h l y \mathrm{~A}$ 
encoding EHEC hemolysin (Schmidt et al., 1995; Møller Nielsen and Thorup Andersen, 2003; Perelle et al., 2004).

\section{Results}

Screening for Shiga toxin genes and serogroups $026,0103,0111,0145$, and 0157 by realtime PCR

Of the 573 fecal samples collected from slaughtered cattle aged between three and 24 months, Shiga toxin genes $(s t x)$ were detected by real-time PCR in 417 samples. The remaining samples tested negative $(n=146)$ or were inhibited $(n=10)$ in the LightCycler-based system. Thus, of 563 samples with available results, $74.1 \%$ tested positive for stx. The proportion of positive samples within the abattoirs ranged from $61.4 \%$ at abattoir D to $83.7 \%$ at abattoir B (Table 2). The nonanalyzable results for both stx- and serogroup-specific assays were due to inhibition of PCR reactions in the LightCycler-based system, a problem not evident in the GeneDisc ${ }^{\circledR}$ system. Amongst the stx-positive samples, serogroups O145, O103, O26, O157, and O111 were detected by real-time PCR in $41.9 \%, 25.9 \%, 23.9 \%, 7.8 \%$, and $0.8 \%$, respectively (Table 3 ). The proportion of samples positive for serogroups $\mathrm{O} 145, \mathrm{O} 103, \mathrm{O} 26$, and $\mathrm{O} 157$ thereby ranged from $31.1 \%$ to $76.0 \%$ (abattoir F), $9.0 \%$ to $50.6 \%$ (abattoir E), $12.5 \%$ to $31.2 \%$ (abattoir E), and $1.3 \%$ to $32.0 \%$ (abattoir F), respectively. Only a few samples from two abattoirs (C, E) tested positive for serogroup O111. In 136 samples one serogroup, in 67 samples two serogroups, and in 22 samples three serogroups were simultaneously found. Six samples tested positive for four serogroups (data not shown).

\section{Strain isolation}

From 95 O26, 166 O145, and 30 O157 PCR-positive samples, 17 O26, 28 O145, and 12 O157 strains were isolated by colony hybridization after immunomagnetic separation. Thus, success 
rates for isolation were $17.9 \%$ for O26 strains, $16.9 \%$ for $\mathrm{O} 145$ strains, and $40.0 \%$ for $\mathrm{O} 157$ strains. The 17 O26 strains were all eae-positive, but only nine of them harbored stx genes (Table 4). Eight $s t x$-positive strains thereby possessed $s t x 1$ and one strain harbored stx2. In addition, 15 O26 strains, including all stx-positive strains, harbored hlyA. Of the 28 O145 strains, more than half were negative for stx 1 , stx2, eae, and hlyA (Table 4). The other ten 0145 strains were eae-positive but only four of them harbored stx genes. Two O145 strains were thereby positive for $s t x 1$ and two for $s t x 2$. Furthermore, five of the 120157 strains harbored stx 2 and eae and did not ferment sorbitol (Table 4). The other seven O157 strains were negative for stx and eae (three strains) or tested positive only for eae (four strains). Six strains were sorbitol fermenting, whereas one eae-positive strain was sorbitol non-fermenting. Of the 120157 strains, seven strains, including four of the five stx2-positive strains, harbored hlyA. Moreover, three of the five stx2-positive/eae-positive 0157 strains and the sorbitol non-fermenting, stxnegative/eae-positive $\mathrm{O} 157$ strain agglutinated with anti-H7 antiserum.

\section{Discussion}

To evaluate the application of a real-time PCR-based system for monitoring of O26, O103, O111, O145, and O157 STEC in young cattle at slaughter, 573 samples were screened for Shiga toxin genes and for the top-five STEC serogroups. Shiga toxin genes were found in almost three quarters $(74 \%)$ of the fecal samples with available results. More than one third of the stx-positive samples tested negative for the top-five serogroups. Comparisons of our results with literature data on the occurrence of STEC and certain serogroups in cattle are hampered by differences in e.g. the target animal population, the sampling strategy, or the detection procedure, but high stx detection rates (up to $71 \%$ ) have also been reported in other studies (Cerqueira et al., 1999; Pradel et al., 2000; Kobayashi et al., 2001). Statistical analysis (Table 2) showed that stx prevalence was significantly influenced by age of slaughtered animals and abattoir. To evaluate 
the reasons of the varying serogroup prevalence between the abattoirs, further investigations are required, especially in view of the high $\mathrm{O} 157$ and $\mathrm{O} 145$ prevalence in one abattoir.

With regard to serogroup distribution, serogroups O26, O103, and O145 were more frequently detected in the present study than $\mathrm{O} 157$ and in particular O111. Other studies also frequently reported E. coli $\mathrm{O} 26$ and $\mathrm{O} 103$ in cattle, whereas serogroup $\mathrm{O} 145$ was less prevalent (Jenkins et al., 2003; Joris et al., 2011). As expected for Switzerland (Al-Saigh et al., 2004; Zweifel et al., 2005), serogroup O157 was not predominant in our bovine samples. A recent study (Käppeli et al., 2011a) investigating human infections with non-O157 STEC in Switzerland reported that serogroup O26 was most frequently isolated (28.9\%) followed by O145 (10.3\%), O103 (6.2\%), and O121 (6.2\%). In contrast to other countries (Elliot et al., 2001; Brooks et al., 2005), serogroup O111 was rarely detected. Besides, it must be considered that STEC of other serogroups as e.g. O91, O113, O121, or O128 play an important role as a cause of human disease in certain regions (Pradel et al., 2000; Beutin et al., 2004; Brooks et al., 2005; Bettelheim, 2007).

To assess the potential pathogenicity of STEC for humans, strain isolation and characterization is of central importance. Simultaneous detection of stx and a certain serogroup in a sample by PCR does not necessarily implicate that these properties are featured by the same strain. A reliable conclusion about STEC shedding in cattle or a potential health hazard can therefore not be drawn based on such results. This fact is also emphasized by the finding of two or more of the top-five STEC serogroups in our stx-positive samples.

For strain isolation, we selected O26, O145, and O157 PCR-positive samples. These serogroups were selected due to our screening results and their relevance in human disease (CDC, 2007; EFSA/ECDC, 2011; Käppeli et al., 2011a,b). Using colony hybridization after immunomagnetic separation, the isolation rate was less than $18 \%$ for $\mathrm{O} 26$ and $\mathrm{O} 145$ strains and about $40 \%$ for $\mathrm{O} 157$ strains. A great deal of time and effort was thereby required to isolate the 28 
O145, 17 O26, and 12 O157 strains. Data directly comparable to our results are lacking in the literature. Barlow and Mellor (2010) used a similar screening approach but serogroup-specific strain isolation by immunomagnetic separation was restricted to only few samples. Basically, different isolation procedures have been proposed for STEC or E. coli of certain serogroups, but fast and reliable strain isolation from animals and food remains a continuous problem (Jenkins et al., 2003; Bettelheim, 2007; Barlow and Mellor, 2010; Fratamico et al., 2011; Verstrate et al., 2012). Noteworthy selective agars for isolation of O26, O103, O111, O145, and sorbitolfermenting O157 E. coli have recently been described (Possé et al., 2008; Joris et al., 2011).

Only a few of the 57 isolated strains showed a virulence pattern of STEC typically associated with human disease. Twenty-one strains (18 of serogroup O145 and three of serogroup O157) were negative for both stx and eae genes. Moreover, eight O26, six O145, and four O157 strains harbored eae but were lacking stx. Cattle thereby constitute an important source of serologically and genetically diverse eae-harboring E. coli (Blanco et al., 2005). Such strains can undergo ephemeral interconversions via loss and gain of Stx-encoding phages, which leads to different pathotypes. This was already shown for E. coli $\mathrm{O} 157$ and E. coli $\mathrm{O} 26$ isolated from human (Bielaszewska et al., 2007; Friedrich et al., 2007; Mellmann et al., 2008). Nevertheless, in a recently published study (Stephan et al., 2009) two stx-negative/eae-positive E. coli strains isolated from a cattle and pig could not be converted to STEC using stx 2 -phages even though each of the strains had an intact phage integration site. Further investigations are required to elucidate the role of animal stx-negative/eae-positive E. coli belonging to STEC serogroups in their natural source and in human infections.

Shiga toxin genes were only detected in about one third of our isolated strains. The proportion of STEC amongst isolates was $14 \%$ for O145 strains, 42\% for O157 strains, and 53\% for O26 strains. Pearce et al. (2006) also reported that carriage of stx in E. coli O145 shed by Scottish cattle was rare $(4.7 \%)$, whereas $49 \%$ of E. coli $\mathrm{O} 26$ isolates possessed stx. The 
infrequent occurrence of Shiga toxin genes in E. coli O145 might partly explain that studies investigating STEC shedding in cattle mainly detected serogroup O145 in low frequencies or not at all (Pradel et al., 2000; Kobayashi et al., 2001; Hornitzky et al., 2002; Blanco et al., 2004b). Amongst our STEC strains that were all eae-positive, STEC O26 mainly harbored only stx 1, STEC O145 either stx 1 or stx2, and STEC O157 only stx2. Bovine STEC O26 can harbor stx 1 and $s t x 2$, but in various studies stx1 predominated (Hornitzky et al., 2002; Blanco et al., 2004b; Pearce et al., 2006; Bardiau et al., 2009). With regard to STEC strains associated with human illnesses in Switzerland (Käppeli et al., 2011a,b), STEC O26 mainly harbored either stx1 or stx2 and eae, STEC O145 mainly possessed stx2 and eae, and STEC O157 featured stx2 alone or in combination with stx 1 and also harbored eae, a pattern typically found in E. coli $\mathrm{O} 157: \mathrm{H} 7$ (Blanco et al., 2004a; Karch et al., 2005; Gilmour et al., 2009). STEC O26 and especially STEC O145 isolated from sporadic cases of human ilnesses are highly heterogeneous as evidenced e.g. by their stx genotypes, plasmid profiles, or plasmid gene composition (Karch et al., 2005).

In summary, using a real-time PCR-based system, Shiga toxin genes were frequently found in fecal samples from young Swiss cattle at slaughter and the top-five STEC serogroups, especially $\mathrm{O} 26, \mathrm{O} 103$, and $\mathrm{O} 145$, were also detected in stx-positive samples. Real-time PCR proved to be suitable for screening purposes but it must be considered that this does not result in a bacterial isolate. By taking into consideration only the screening results without strain isolation, a distorted impression on the occurrence of STEC O26, O103, O111, O145, and O157 in the cattle population would have resulted. However, fast and reliable isolation of respective strains poses a major challenge. Success rates for strain isolation from our samples were low and only few of the isolated strains showed a virulence pattern of STEC pathogenic to humans. The value of STEC monitoring aimed at the top-five serogroups with the described approach in slaughtered cattle remains therefore challenging. In particular, methods must be improved to obtain more efficiently isolated strains, which are a prerequisite to assess the pathogenic traits. 


\section{Acknowledgments}

We thank the staff of the abattoirs for their assistance with the collection of data and Sonja Hartnack from the Section of Epidemiology, Vetsuisse Faculty University of Zurich, for her assistance with statistical analysis. This study was partly funded by the Swiss Federal Veterinary Office.

\section{References}

Al-Saigh, H., C. Zweifel, J. Blanco, J. E. Blanco, M. Blanco, M. S. Usera, and R. Stephan, 2004: Fecal shedding of Escherichia coli O157, Salmonella, and Campylobacter in Swiss cattle at slaughter. J. Food Prot. 67, 679-684.

Bardiau, M., S. Labrozzo, and J. G. Mainil, 2009: Putative adhesins of enteropathogenic and enterohemorrhagic Escherichia coli of serogroup O26 isolated from humans and cattle. J. Clin. Microbiol. 47, 2090-2096.

Barlow, R. S., and G. E. Mellor, 2010: Prevalence of enterohemorrhagic Escherichia coli serotypes in Australian beef cattle. Foodborne Pathog. Dis. 7, 1239-1245.

Bettelheim, K. A., 2007: The non-O157 Shiga-toxigenic (verotoxigenic) Escherichia coli; Under-rated pathogens. Crit. Rev. Mircobiol. 33, 67-87.

Beutin, L., 2006: Emerging enterohaemorrhagic Escherichia coli, causes and effects of the rise of a human pathogen. J. Vet. Med. B 53, 299-305.

Beutin, L., S. Jahn, and P. Fach, 2009: Evaluation of the 'GeneDisc' real-time PCR system for detection of enterohaemorrhagic Escherichia coli (EHEC) O26, O103, O111, O145 and O157 strains according to their virulence markers and their O- and H-antigen-associated genes. J. Appl. Microbiol. 106, 1122-1132.

Beutin, L., G. Krause, S. Zimmermann, S. Kaulfuss, and K. Gleier, 2004: Characterization of Shiga toxin-producing Escherichia coli strains isolated from human patients in Germany over a 3-year period. J. Clin. Microbiol. 42 , 1099-1108.

Bielaszewska, M., R. Prager, R. Köck, A. Mellmann, W. Zhang, H. Tschäppe, P. I. Tarr, and H. Karch, 2007: Shiga toxin gene loss and transfer in vitro and in vivo during enterohemorrhagic Escherichia coli O26 infection in humans. Appl. Environ. Microbiol. 73, 3144-3150. 
Blanco, J. E., M. Blanco, M. P. Alonso, A. Mora, G. Dahbi, M. A. Coira, and J. Blanco, 2004a: Serotypes, virulence genes, and intimin types of Shiga toxin (verotoxin)-producing Escherichia coli isolates from human patients: Prevalence in Lugo, Spain, from 1992 through 1999. J. Clin. Microbiol. 42, 311-319.

Blanco, M., J. E. Blanco, A. Mora, G. Dahbi, M. P. Alonso, E. A. González, M. I. Bernárdez, and J. Blanco, 2004b: Serotypes, virulence genes, and intimin types of Shiga toxin (Verotoxin)-producing Escherichia coli_isolates from cattle in Spain and identification of a new intimin variant gene (eae- $\xi$ ). J. Clin. Microbiol. 42, 645-651.

Blanco, M., S. Schumacher, T. Tasara, C. Zweifel, J. E. Blanco, G. Dahbi, J. Blanco, and R. Stephan, 2005: Serotypes, intimin variants and other virulence factors of eae positive Escherichia coli strains isolated from healthy cattle in Switzerland. Identification of a new intimin variant gene (eae- $\eta 2)$. BMC Microbiol. 5:23.

Brooks, J. T., E. G. Sowers, J G. Wells, K. D. Greene, P. M. Griffin, R. M Hoekstra, and N. A. Strockbine, 2005: Non-O157 Shiga toxin-producing Escherichia coli infections in the United States, 1983-2002. J. Infect. Dis. $192,1422-1429$.

Caprioli, A., A. Morabito, H. Brugère, and E. Oswald, 2005: Enterohaemorrhagic Escherichia coli: Emerging issues on virulence and modes of transmission. Vet. Res. 36, 289-311.

CDC, Centers for Disease Control and Prevention, 2007: Bacterial foodborne and diarrheal disease national case surveillance. Annual Report, 2005. Atlanta: U.S. Department of Health and Human Services, Centers for Disease Control and Prevention.

Cerqueira, A. M. F., B. E. C. Guth, R. M. Joaquim, and J. R. C. Andrade, 1999: High occurrence of Shiga toxinproducing Escherichia coli (STEC) in healthy cattle in Rio de Janeiro State, Brazil. Vet. Microbiol. 70, 111121.

EFSA, European Food Safety Authority, 2009: Technical specifications for the monitoring and reporting of verotoxigenic Escherichia coli (VTEC) on animals and food (VTEC surveys on animals and food). EFSA Journal 1366.

EFSA/ECDC, European Food Safety Authority/European Center for Disease Prevention and Control, 2011: The European Union summary report on trends and sources of zoonoses, zoonotic agents and food-borne outbreaks in 2009. EFSA Journal 2090.

Elliott, E. J., R. M. Robins-Browne, E. V. O’Loughlin, V. Bennett-Wood, J. Bourke, P. Henning, G. G. Hogg, J. Knight, H. Powell, and D. Redmond, 2001: Nationwide study of haemolytic uraemic syndrome: Clinical, microbiological, and epidemiological features. Arch. Dis. Child. 85, 125-131.

Fratamico, P. M., L. K. Bagi, W. C. Cray, Jr., N. Narang, X. Yan, M. Medina, and Y. Liu, 2011: Detection by 
multiplex real-time polymerase chain reaction assays and isolation of Shiga toxin-producing Escherichia coli serogroups O26, O45, O103, O111, O121, and O145 in ground beef. Foodborne Pathog. Dis. 8, 601-607.

Friedrich, A. W., M. Bielaszewska, W. Zhang, M. Pulz, T. Kuczius, A. Ammon, and H. Karch, 2002: Escherichia coli harboring Shiga toxin 2 gene variants: Frequency and association with clinical symptoms. J. Infect. Dis. $185,74-84$.

Friedrich, A. W., W. Zhang, M. Bielaszewska, A. Mellmann, R. Köck, A. Fruth, H. Tschäpe, and H. Karch, 2007: Prevalence, virulence profiles, and clinical significance of Shiga toxin-negative variants of enterohemorrhagic Escherichia coli 0157 infection in humans. Clin. Inf. Dis. 45, 39-45.

Gilmour, M. W., L. Chui, T. Chiu, D. M. Tracz, K. Hagedorn, L. Tschetter, H. Tabor, L. K. Ng, and M. Louie, 2009: Isolation and detection of Shiga toxin-producing Escherichia coli in clinical stool samples using conventional and molecular methods. J. Med. Microbiol. 58, 905-911.

Hornitzky, M. A., B. A. Vanselow, K. Walker, K. A. Bettelheim, C. Corney, P. Gill, G. Bailey, and S. P. Djordjevic, 2002: Virulence properties and serotypes of Shiga toxin-producing Escherichia coli from healthy Australian cattle. Appl. Envrion. Mircobiol. 68, 6439-6445.

Jenkins, C., M. C. Pearce, A. W. Smith, H. I. Knight, D. J. Shaw, T. Cheasty, G. Foster, G. J. Gunn, G. Dougan, H. R. Smith, and G. Frankel, 2003: Detection of Escherichia coli serogroups O26, O103, O111 and O145 from bovine faeces using immunomagnetic separation and PCR/DNA probe techniques. Lett. Appl. Microbiol. 37, 207-212.

Johannes, L., and W. Römer, 2010: Shiga toxins - from cell biology to biomedical applications. Nat. Rev. Microbiol. 8, 105-116.

Johnson, K. E., C. M. Thorpe, and C. L. Sears, 2006: The emerging clinical importance of non-O157 Shiga toxinproducing Escherichia coli. Clin. Infect. Dis. 43, 2587-1595.

Joris, M. A., D. Pierard, and L. De Zutter, 2011: Occurrence and virulence patterns of E. coli O26, O103, O111 and O145 in slaughter cattle. Vet. Microbiol. 151, 418-421.

Kaper, J. B., J. P. Nataro, and H. L. T. Mobley, 2004: Pathogenic Escherichia coli. Nat. Rev. Microbiol. 2, $123-140$.

Käppeli, U., H. Hächler, N. Giezendanner, L. Beutin, and R. Stephan, 2011a: Human Infections with non-O157 Shiga Toxin-producing Escherichia coli, Switzerland, 2000-2009. Emerg. Infect. Dis. 17, 180-185.

Käppeli, U., H. Hächler, N. Giezendanner, T. Cheasty, and R. Stephan, 2011b: Shiga toxin-producing Escherichia coli $\mathrm{O} 157$ associated with human infections in Switzerland, 2000-2009. Epidemiol. Infect. 139, 1097-1104.

Karch, H., P. I. Tarr, and M. Bielaszewska, 2005: Enterohaemorrhagic Escherichia coli in human medicine. Int. J. 
Med. Microbiol. 295, 405-418.

Karmali M. A., V. Gannon, and J. M. Sargeant JM, 2010: Verocytotoxin-producing Escherichia coli (VTEC). Vet. Microbiol. 140, 360-370.

Kobayashi, H., J. Shimada, M. Nakazawa, T. Morozumi, T. Pohjanvirta, S. Pelkonen, and K. Yamamoto, 2001: Prevalence and characteristics of Shiga toxin-producing Escherichia coli from healthy cattle in Japan. Appl. Environ. Microbiol. 67, 484-489.

Mellmann, A., S. Lu, H. Karch, J. Xu, D. Harmsen, M. A. Schmidt, and M. Bielaszewska, 2008: Recycling of Shiga toxin 2 genes in sorbitol-fermenting enterohemorrhagic Escherichia coli O157:NM. Appl. Environ. Microbiol. $74,67-72$.

Møller Nielsen, E., and M. Thorup Andersen, 2003: Detection and characterization of verocytotoxin-producing Escherichia coli by automated 5' nuclease PCR assay. J. Clin. Microbiol. 41, 2884-2893.

Orth, D., K. Grif, A. B. Khan, A. Naim, M. P. Dierich, and R. Würzner, 2007: The Shiga toxin genotype rather than the amount of Shiga toxin or the cytotoxicity of Shiga toxin in vitro correlates with the appearance of the haemolytic uremic syndrome. Diagn. Microbiol. Infect. Dis. 59, 235-242.

Pearce, M. C., J. Evans, I. J. McKendrick, A. W. Smith, H. I. Knight, D. J. Mellor, M. E. J. Woolhouse, G. J. Gunn, and J. C. Low, 2006: Prevalence and virulence factors of Escherichia coli serogroup O26, O103, O111, and O145 shed by cattle in Scotland. Appl. Environ. Microbiol. 72, 653-659.

Perelle, S., F. Dilasser, J. Grout, and P. Fach, 2003: Development of a 50-nuclease PCR assay for detecting Shiga toxin-producing Escherichia coli O145 based on the identification of an "O-island 29" homologue. J. Appl. Microbiol. 94, 587-94.

Perelle, S., F. Dilasser, J. Grout, and P. Fach, 2004: Detection by 5'-nuclease PCR of Shiga-toxin producing Escherichia coli O26, O55, O91, O103, O111, O113, O145 and O157:H7, associated with the world's most frequent clinical cases. Mol. Cell. Probes 18, 185-192.

Perelle, S., F. Dilasser, J. Grout, and P. Fach, 2005: Detection of Escherichia coli_serogroup O103 by real-time polymerase chain reaction. J. Appl. Microbiol. 98, 1162-1168.

Possé, B., L. De Zutter, M. Heyndrickx, and L. Herman, 2008: Novel differential and confirmation plating media for Shiga toxin-producing Escherichia coli serotypes O26, O103, O111, O145 and sorbitol-positive and -negative O157. FEMS Microbiol. Lett. 124-131.

Pradel, N., V. Livrelli, C. de Champs, J. Palcoux, A. Reynaud, F. Scheutz, J. Sirot, B. Joly, and C. Forestier, 2000: Prevalence and characterization of Shiga toxin-producing Escherichia coli_isolated fro cattle, food, and children 
during a one-year prospective study in France. J. Clin. Microbiol. 38, 1023-1031.

Schmidt, H., L. Beutin, and H. Karch, 1995: Molecular analysis of the plasmid-encoded hemolysin of Escherichia coli O157:H7 strain EDL 933. Infect. Immun. 63, 1055-1061.

Stephan, R., W. Zhang, M. Bielaszewska, A. Mellmann, and H. Karch, 2009: Phenotypic and genotypic traits of Shiga toxin-negative E. coli O157:H7/H- bovine and porcine strains. Foodborne Pathog. Dis. 6, 235-243.

Tarr, P. I., C. A. Gordon, and W. L. Chandler, 2005: Shiga-toxin-producing Escherichia coli and haemolytic uraemic syndrome. Lancet 365, 1073-1086.

Verstrate, K. J. Robyn, J. Del-Favero, P. De Rijk, M. A. Joris, L. Herman, M. Heyndrickx, L. De Zutter, and K. De Reu, 2012: Evaluation of a multiplex-PCR detection in combination with an isolation method for STEC O26, O103, O111, O145 and sorbitol fermenting O157 in food. Food Microbiol. 29, 49-55.

Zweifel, C., S. Schumacher, M. Blanco, J. E. Blanco, T. Tasara, J. Blanco, and R. Stephan, 2005: Phenotypic and genotypic characteristics of non-O157 Shiga toxin-producing Escherichia coli (STEC) from Swiss cattle. Vet. Microbiol. 105, 37-45. 


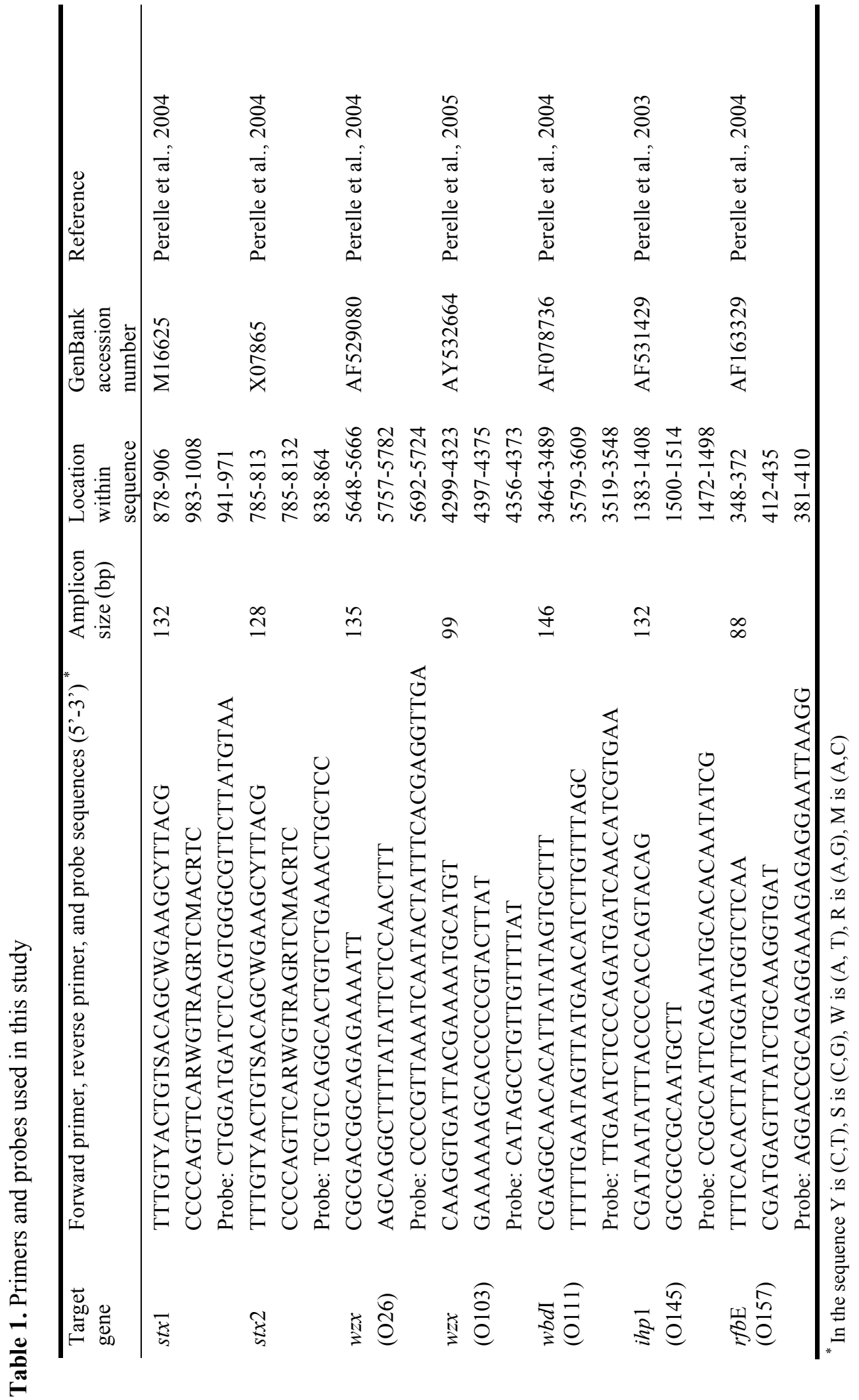


Table 2. Detection of stx genes encoding Shiga toxins by real-time PCR in bovine fecal samples obtained from different abattoirs

\begin{tabular}{|c|c|c|c|}
\hline & $\begin{array}{l}\text { No. of examined } \\
\text { samples }\end{array}$ & $\begin{array}{l}\text { No. of analyzable } \\
\text { samples }\end{array}$ & $\begin{array}{l}\text { No. }(\%) \text { of } s t x- \\
\text { positive samples* }\end{array}$ \\
\hline Abattoir A & 102 & 96 & $67 \quad(69.8 \%)$ \\
\hline Abattoir B & 104 & 104 & $87 \quad(83.7 \%)$ \\
\hline Abattoir C & 104 & 103 & $83 \quad(80.6 \%)$ \\
\hline Abattoir D & 104 & 101 & $62(61.4 \%)$ \\
\hline Abattoir E & 97 & 97 & $77 \quad(79.4 \%)$ \\
\hline Abattoir F & 36 & 36 & $25 \quad(69.4 \%)$ \\
\hline Abattoir G & 26 & 26 & $16(61.5 \%)$ \\
\hline Total & 573 & 563 & $417(74.1 \%)$ \\
\hline
\end{tabular}

* Prevalence of stx was significantly influenced by age of slaughtered animals $(\mathrm{p}<0.0001)$ and abattoir $(\mathrm{p}=0.024)$, whereas the interaction between age and abattoir was not significant $(\mathrm{p}=0.082)$. Analysis was performed using a logistic regression approach with presence or absence of stx as outcome variable and abattoir, age and an interaction between age and abattoir as explanatory variables or fixed effects. Model selection was based on Akaike's information criterion with lower values indicating a better model fit. P-values were derived from likelihood ratio tests.

Table 3. Detection of serogroups O26, O103, O111, O145, and O157 by real-time PCR in 417 stx-positive, bovine fecal samples

\begin{tabular}{|c|c|c|c|c|c|}
\hline & \multicolumn{5}{|c|}{ Serogroup } \\
\hline & $\mathrm{O} 26$ & $\mathrm{O} 103$ & O111 & $\mathrm{O} 145$ & $\mathrm{O} 157$ \\
\hline $\begin{array}{l}\text { No. of analyzable } \\
\text { samples }\end{array}$ & 397 & 394 & 384 & 396 & 385 \\
\hline $\begin{array}{l}\text { No. (\%) of samples with } \\
\text { detection of the specific } \\
\text { serogroup* }\end{array}$ & $\begin{array}{l}95 \\
(23.9 \%)^{A}\end{array}$ & $\begin{array}{l}102 \\
(25.9 \%)^{A}\end{array}$ & $\begin{array}{l}3 \\
(0.8 \%)^{\text {в }}\end{array}$ & $\begin{array}{l}166 \\
(41.9 \%)^{C}\end{array}$ & $\begin{array}{l}30 \\
(7.8 \%)^{\mathrm{D}}\end{array}$ \\
\hline
\end{tabular}

* Values with different letters were significantly different (Chi Square test/Fishers exact test, $\mathrm{P}<0.05$ ) 
Table 4. Occurrence of stx and eae genes among 17 isolated O26 strains, 28 isolated O145 strains, and 12 isolated $\mathrm{O} 157$ strains

\begin{tabular}{|c|c|c|c|c|c|}
\hline Serogroup & $\begin{array}{l}\text { No. of } \\
\text { strains }\end{array}$ & $s t x 1$ & stx 2 & eae & hlyA \\
\hline \multirow[t]{4}{*}{026} & $8^{\circ}$ & + & - & + & + \\
\hline & $6^{\circ}$ & - & - & + & + \\
\hline & $2^{\circ}$ & - & - & + & - \\
\hline & $1^{\circ}$ & - & + & + & + \\
\hline \multirow[t]{5}{*}{0145} & $16^{\circ}$ & - & - & - & - \\
\hline & $6^{\circ}$ & - & - & + & + \\
\hline & $2^{\circ}$ & + & - & + & + \\
\hline & $2^{\circ}$ & - & + & + & + \\
\hline & $2^{\circ}$ & - & - & - & + \\
\hline \multirow[t]{6}{*}{0157} & $4 *$ & - & + & + & + \\
\hline & $3^{\circ}$ & - & - & - & - \\
\hline & $2^{\circ}$ & - & - & + & + \\
\hline & $1 *$ & - & + & + & - \\
\hline & $1 *$ & - & - & + & + \\
\hline & $1^{\circ}$ & - & - & + & - \\
\hline
\end{tabular}

${ }^{\circ}$ sorbitol fermenting

* sorbitol non-fermenting 


\section{Acknowledgements}

I would like to express my gratitude to all those who contributed to this work.

Special thanks go to:

Prof. Roger Stephan, Institute for Food Safety and Hygiene, Vetsuisse Faculty University of Zürich, for giving me the opportunity to work on this scientific project, for his optimistic support and help when ever needed.

PD Dr. Claudio Zweifel, Institute for Food Safety and Hygiene, Vetsuisse Faculty University of Zürich, for his patience, for his help whenever necessary and for the preparation of the main review.

The whole ILS Team for their assistance and creation of a friendly working atmosphere.

All the other $\mathrm{PhD}$ and doctoral thesis students for the good times.

My parents Vreni and Hansueli Hofer-Rohner for their care and appreciation. 


\section{Curriculum Vitae}

$\begin{array}{ll}\text { Name } & \text { Eveline, Hofer } \\ \text { Geburtsdatum } & \text { 9. März 1986 } \\ \text { Geburtsort } & \text { Herisau AR } \\ \text { Nationalität } & \text { Schweizerin } \\ \text { Heimatort } & \text { Langnau i. E. }\end{array}$

8/1993-7/2001 Primar- und Sekundarschule, Wattwil, Schweiz

8/2001-7/2005 Kantonsschule, Wattwil, Schweiz

7.7.2005 Erlangung der Maturität an der Kantonsschule Wattwil, Schwerpunkt

Biologie und Chemie

10/2005-10/2010 Studium der Veterinärmedizin an der Vetsuisse-Fakultät, Universität Zürich, Schweiz

14.10.2010 Erlangung des Diploms für Tierärzte an der Vetsuisse-Fakultät, Universität Zürich, Schweiz

11/2010-11/2011 Anfertigung der Dissertation unter der Leitung von Prof. Dr. Roger Stephan am Institut für Lebensmittelsicherheit und -hygiene der Vetsuisse-Fakultät, Universität Zürich, Schweiz

11/2010-1/2010 Assistentin am Institut für Lebensmittelsicherheit und -hygiene der Vetsuisse-Fakultät, Universität Zürich, Schweiz 